\title{
Consumo de produtos sustentáveis: Percepções dos consumidores sobre a embalagem Natura Ekos de Buriti
}

Consumption of sustainable products: Consumer perceptions of Natura Ekos de Buriti packaging

RODRIGUES, Priscila Westphal; Mestre em Design, UNISINOS

Priscila@priwdesign.com.br

\section{Resumo}

Este artigo apresenta uma pesquisa de caráter exploratório, que buscou investigar a percepção dos consumidores de produtos Natura Ekos, utilizando como objeto de estudo a embalagem de Frescor com óleo fixo de Buriti. Para tanto, apoia-se no processo de significação para investigar os significados simbólicos agregados ao produto que remetem à sustentabilidade, a partir da realização de entrevistas em profundidade. Os principais resultados apontam que os significados simbólicos podem potencializar a comunicação de sustentabilidade em embalagens por meio de intervenções de design, tendo em vista uma cultura de consumo mais sustentável para o bemestar coletivo.

Palavras Chave: sustentabilidade; consumo sustentável; significados simbólicos; percepção dos usuários; Natura Ekos.

\begin{abstract}
This article presents an exploratory research that sought to investigate the perception of consumers of Natura Ekos products, using as a study object the freshness package with Buriti fixed oil. In order to do so, it relies on the process of signification to investigate the symbolic meanings added to the product that refer to sustainability, based on in-depth interviews. The main results point out that the symbolic meanings can potentiate the communication of sustainability in packaging through design interventions, in view of a more sustainable consumption culture for collective well-being.
\end{abstract}

Keywords: sustainability; sustainable consumption; symbolic meanings; perception of users; Natura Ekos.

\section{Introdução}

A sustentabilidade tem conquistado espaço de alta relevância no cenário mundial e na mídia por meio de debates sobre como amenizar os impactos ambientais que degradaram e extinguiram uma quantidade considerável de recursos naturais e que ainda continuam sendo explorados em busca do progresso da sociedade. A busca incessante por benefícios econômicos, acima dos interesses sociais e ambientais, consolida características de uma sociedade cada vez mais individualista, que se distancia dos interesses para bem-estar coletivo. 
A empresa Natura foi selecionada para esta pesquisa porque trata-se de uma empresa brasileira reconhecida nacional e internacionalmente pela produção de cosméticos com baixo impacto ambiental. Como estratégia de competitividade utiliza o discurso da sustentabilidade para comunicar produtos e serviços e estimular novas relações de bem-estar entre usuários, fornecedores e revendedores (NATURA, 2013).

Por essa razão, procurou-se investigar a percepção dos usuários consumidores de produtos Natura Ekos, a fim de explorar os significados simbólicos, agregados na embalagem do produto Frescor com óleo fixo de Buriti, que remetem à sustentabilidade.

A revisão de literatura parte da contextualização sobre cultura de consumo na sociedade contemporânea, com base em Baudrillard (2007), Campbell (2006), Douglas \& Isherwood (2006), Lipovetski (2004), McCraken (2003) e Miller (2007). A abordagem do processo de significação utiliza principalmente Bourdieu $(1989,2007)$. O presente artigo é resultado de uma pesquisa exploratória, que utilizou como método, entrevistas em profundidade com 12 consumidoras.

Os principais resultados apontam que os processos de significação revelam significados simbólicos que podem potencializar a comunicação de sustentabilidade nas embalagens por meio de intervenções de design, tendo em vista uma cultura de consumo mais sustentável para o bemestar coletivo, com equilíbrio econômico, ambiental e social.

\section{Por uma Cultura de Consumo mais Sustentável}

No século XVIII, as propriedades simbólicas dos bens de consumo tomaram novos significados e o processo de tomada de decisão era realizado cada vez mais pelo status apoiado na estética, influenciando significativamente o processo de compra. O século XIX trouxe consigo vícios que marcaram o consumismo voltado para a sedução e o desejo, muito além da satisfação das necessidades, no qual o querer substitui o necessário e liberta o princípio de prazer como um desejo insaciável. Baudrillard (2007), McCraken (2003) e Miller (2007) concordam que a sociedade de consumo depende do consumo de significados em um mundo culturalmente constituído. Campbell (2006) reforça que a sociedade de consumo proporciona significados e identidades, na qual se busca insaciavelmente associar significados para a conquista do prazer, que tem como efeito, uma crise de identidade.

Douglas \& Isherwood (2006) contrapõem e afirmam que o mundo dos bens tem como função dar sentido, e com isso pretende "dar visibilidade e estabilidade às categorias de cultura" porque "as coisas, cuja posse significa riqueza, não são necessárias por elas mesmas, mas pelas relações sociais que elas sustentam" onde "a pobreza é culturalmente definida, não por um inventário de objetos, mas por um padrão de exclusões, geralmente bem sistemáticas". Exploram também, os significados do consumo presentes no cotidiano que contribuem para estruturação de valores, construção de identidades, regulações das relações sociais e definições de mapas culturais que podem auxiliar na busca de novos contextos.

Campbell (2006), McCraken (2003) e Miller (2007) consideram que o consumo moderno é um artefato histórico, que permite investigar as origens, o desenvolvimento do consumo e ainda gerar reflexões mais profundas, além do ato de compra. Campbell (2006) e Baudrillard (2007) consideram que o consumo está ligado às relações de ser e saber para o atendimento das necessidades e a satisfação dos desejos. Bourdieu (1989) associa esta relação de ser e saber com o 
capital cultural do indivíduo, onde o movimento ideológico e a política direcionada ao mercado proporciona escolhas para o consumo.

Neste sentido, pontua-se que o movimento ideológico e político atual encontra-se dividido num conflito entre o progresso com ênfase econômica e o progresso com ênfase no desenvolvimento sustentável, o qual requer que as relações para o progresso futuro sejam radicalmente repensadas, tais como poder e consumo. Entende-se por desenvolvimento sustentável a definição proposta pela ONU - Organização das Nações Unidas que indica a satisfação das necessidades, sem comprometer a capacidade de regeneração do Planeta Terra para que as próximas gerações também possam usufruir do meio ambiente com qualidade de vida. Este é o paradigma que marcou a transição do final do século XX e o início do século XXI, cujo desafio deve ser enfrentado pela sociedade contemporânea. Para que as escolhas alinhem-se com o desenvolvimento sustentável, deve-se refletir sobre os efeitos do Homo Consumericus que foram e ainda são fortemente apropriados pelas mídias, marcando uma aproximação do consumo mais hedônico como estratégia para influenciar a compra.

Neste ponto, Douglas \& Isherwood (2006) e Lipovetski (2004) exploram que o sujeito possui a necessidade de ter algo para ser feliz e para a satisfação das necessidades. Lipovetski (2004) afirma que agora tudo é hiper e as necessidades precisam ser atendidas imediatamente. Revela ainda a necessidade de mudança com uma reorganização profunda no modo de funcionamento cultural e social.

De modo geral, compreende-se que esta relação de felicidade e bem-estar apontada tem sido conduzida de modo insustentável, em virtude das características individualistas e influências do consumo hedônico, que somam-se com o aumento populacional e acesso à diversidade de bens. Com isso, o consumo torna-se uma demanda insaciável, ignorando que o Planeta não possui recursos para suprir tais necessidades em escala, se mudanças radicais não forem realizadas.

Para Baudrillard (2007) e Douglas \& Isherwood (2006), o consumo está ligado ao consumo de tempo. Lipovetski (2004) acrescenta que a renovação da sociedade está ligada à vivência no tempo diante dos excessos, onde tudo é descartável. Para isso, propõe a construção de uma cultura de prevenção e de resgate da ética para o futuro, na qual ressalta que o ecodesenvolvimento tem demonstrado suas primeiras ações.

Miller (2007) aponta que o consumo se tornou o pivô da contradição dialética, o problemachave contemporâneo, o responsável pelo sofrimento em massa e desigualdade. O autor (2007) rebate as questões, afirmando que o consumo pode tornar-se a solução futura, um movimento progressivo do mundo, um estímulo para que as instituições sejam responsáveis, tendo em vista ações que objetivem dissolver a visão de consumo como algo maléfico. Assim, aponta implicações positivas compreendidas a partir do consumo, como a influência do design e da arquitetura, a desfechitização da mercadoria e as relações do homem com o objeto.

Do ponto de vista da sustentabilidade, considera-se como pressuposto, a necessidade de repensar o consumo, as relações e os significados para realizar mudanças radicais considerando o consumo sustentável dentro das capacidades de regeneração do Planeta sem que a sociedade retorne a uma era primitiva. Pontua-se que o designer tem como compromisso a concepção de projetos de design que contribuam para a construção de uma nova cultura de consumo que possa alimentar e educar o senso comum por meio de produtos e serviços, considerando o bem-estar coletivo da sociedade contemporânea. Para aprofundar as discussões sobre o consumo 
sustentável tendo em vista o processo de significação, apresenta-se uma análise de design das embalagens Natura Ekos.

\section{O Processo de Significação e as Embalagens Natura Ekos}

Como fundamento do consumo, Baudrillard (2007), explora o processo de significação e de comunicação e o processo de classificação e diferenciação social, pelos quais correspondem o sistema de signos e o sistema de necessidades, numa relação de cultura e poder. McCraken (2003) reforça que os significados são estruturados em categorias culturais que correspondem às coordenadas do significado, da representação de distinções básicas e em princípios culturais que correspondem aos pressupostos e às ideias organizadas capazes de diferenciar os fenômenos culturais.

Baudrillard (2007), acrescenta ainda, que os objetos produzem signos carregados de sentidos para tornarem-se visíveis. Para o autor, os signos são mercadorias e estão carregadas de valores simbólicos superproduzidos e manipulados. Em virtude do capitalismo, transformaram-se em commodity sign, ou seja, o sujeito possui autonomia somente por meio dos signos manipulados pela mídia. Pontua-se que a superprodução e reprodução excessiva de imagens estetiza a realidade como se fosse hiperreal.

Bourdieu (1989) e Douglas \& Isherwood (2006) opõem-se à Baudrillard (2007) e argumentam que o consumo funciona como marcador social. Bourdieu (1989) aprofunda que os bens estão ligados às práticas de consumo num sistema de dominação e submissão na criação das relações sociais, no qual o sujeito está no centro do imaginário cultural se manifestando para o coletivo.

Assim, para ressignificar as relações para o bem-estar coletivo, recorta-se a crítica realizada por Morin (2000, p. 70) ao modo técnico-econômico da sociedade, onde o desenvolvimento chega a um ponto insustentável, inclusive o chamado desenvolvimento sustentável. Para resolver a questão, o autor aponta a necessidade de construir uma noção mais rica e complexa sobre o desenvolvimento, que seja não somente material, mas intelectual, afetiva, moral. Neste ponto, é que reforça-se a importância da sustentabilidade como conceito e do consumo sustentável como uma prática a ser potencializada.

Para isso, explora-se a Teoria dos Gostos proposta por Bourdieu (1989) e recorta-se os principais conceitos como campos, habitus e capital cultural. O conceito de campos é definido como as linguagens, condutas, regras e crenças que se organizam, se mantém, se legitimam e se reconhecem dentro de um campo. A ideia de campo traz mais materialidade ao conceito de sustentabilidade. $O$ campo da sustentabilidade é a própria natureza e como sua interação com os indivíduos pode gerar valores simbólicos. Associa-se estes valores simbólicos aos conflitos gerados pelo campo da sustentabilidade com outros campos em decorrência de movimentos ideológicos, nas relações de cultura e poder. Compreende-se que nos conflitos com o campo da sustentabilidade, a inovação pode surgir e contribuir para a atualização e a explicitação das regras direcionadas para o consumo sustentável.

Sob os campos sociais, Bourdieu (1989) define como capital cultural, a construção de uma reflexão, a recontextualização, a problematização ou a acumulação de um conhecimento como uma orientação para o significado que envolve a produção simbólica que pode ser herdada ou 
adquirida. Holt (1998) evidencia que diferentes capitais operam, como um jogo de status multidimensional formado pelo capital econômico, capital social e capital cultural e constituem os habitus. O autor, afirma que o habitus são como um "sistema de disposições duráveis e transponíveis que, integrando todas as experiências passadas, funciona a cada momento como uma matriz de percepções, apreciações e ações, e torna possível a realização de tarefas infinitamente diferenciadas".

Compreende-se que o habitus funciona como um esquema de ação, percepção, reflexão e comportamento, no qual destaca-se a postura e os gestos (hexis), as formas de ver e classificar da coletividade de um determinado campo (ethos princípios e valores), operando distinções que orientam os sentimentos e os desejos em um dado contexto. Assim é possível investigar como os sujeitos se posicionam diante do campo da sustentabilidade, de acordo com a influência do seu capital cultural atual nas práticas sociais. Considera-se que o sujeito está em ação. Por isso, exprime as marcações das práticas sociais no tempo, de modo estruturado, organizado e classificado para o consumo de objetos.

Neste ponto, Holt (1998) afirma que o padrão de consumo varia de acordo com o capital cultural, no qual destaca que o processo de significação do objeto envolve o que as pessoas aprendem, adquirem e experimentam sobre o consumo. Aponta ainda, que os gostos são formados pelas preferências e desejos que ultrapassam as estratégias de ação.

Bourdieu (1989, p.9) aprofunda que, o sistema simbólico tem a função de explicitar o simbolismo, autenticar sua função política e não se reduzir à comunicação. Para tanto, propõe instrumentos simbólicos para compreensão dos significados por meio de formas simbólicas de estruturas subjetivas para o consenso, e de objetos simbólicos de estruturas objetivas que exploram a comunicação e as ideologias. Ressalta que o poder simbólico "é, com efeito, esse poder invisível, que dá sentido para as interações", que nem sempre este poder é visível aos olhos, mas que está em toda parte ou em parte alguma, capaz de construir a realidade através do universo simbólico e de produções simbólicas que marcam o tempo, o simbolismo e o sentido imediato do mundo. Por isso, objetos e mercadorias são signos para a produção de efeitos de sentidos em um dado contexto.

Trazendo essas reflexões para o design, o profissional pode explorar os significados simbólicos criando condições para a geração de cenários mais complexos que potencializem o consumo sustentável por meio de produtos e serviços carregados de significados. Construir esse poder simbólico é dar vida ao objeto, representar valores, crenças e ideologias numa movimentação dada pela sua diversidade de signos com duração determinada pela cultura. De acordo com Bourdieu (1989), os signos são representações sociais que podem transpor mensagens de superfície e subliminares com indícios figurativos, textos, imagens. Os símbolos exibem argumentos que não precisam ser ditos. Sua reflexão busca compreender o que está dito e o que não foi dito claramente. Estes constituem-se por meio de associações de um grupo, de associações ao sentido simbólico, como uma forma de expressão. A legitimidade encontra-se na tentativa de reconhecimento e de coerência.

Portanto, os símbolos funcionam como instrumentos de integração social, como instrumentos de conhecimento e de comunicação de acordo com o sentido que é atribuído pela ordem social por meio de uma integração lógica e moral. Dentro deste contexto da cultura, cria-se um movimento que faz com que as pessoas reconheçam determinados significados que vão se 
naturalizando como uma extratificação social. Se o sujeito não reconhece, não se sente a vontade ao olhar para o símbolo, não reconhece os significados e não são compreendidos, mesmo que eles estejam presentes.

Desse modo, entende-se que o design de embalagens pode potencializar projetos de produtos e serviços com a inserção de uma nova cultura favorecendo a compreensão de aspectos ambientais, estimulando a aprendizagem social com forte apelo ambiental, a fim de repensar o consumo, a comunicação, a reciclagem, o co-processamento e desafiar os ciclos de vida dos produtos contemporâneos com a minimização da exploração de recursos naturais.

A embalagem possui uma dimensão social e pode impulsionar o consumo sustentável diante do paradigma atual. Considera-se as diversas funções da embalagem, como proteção, acondicionamento, transporte, garantia, promoção, dosagem, identificação, comercialização e entrega. Destaca-se ainda, sua capacidade de penetração e acessibilidade em diferentes camadas sociais, marcadas pelas representações gráficas na qual os usuários atribuem significados simbólicos. A partir deste contexto, busca-se novas perspectivas para impulsionar o consumo sustentável e potencializar a comunicação de sustentabilidade por meio das embalagens.

Por esta razão, recorta-se a empresa Natura, que busca o reconhecimento da sociedade de um modo geral pela sua performance. Tem como foco do negócio, a produção de cosméticos de higiene pessoal, perfumaria e beleza, que busca constantemente inovações de baixo impacto ambiental e alta relevância social. Objetiva ainda, a construção de uma comunicação transparente com seus usuários, estimulando novos hábitos de consumo (NATURA, 2013). As estratégias de comercialização dos produtos e serviços tem como intuito a promoção de relações de bem-estar que exploram significados simbólicos que permeiam o resgate do homem com a natureza, como é o caso da linha Natura Ekos (NATURA EKOS, 2013).

Busca-se, portanto, investigar os processos de significação para revelar significados simbólicos que potencializem a comunicação de sustentabilidade das embalagens, tendo em vista o bem-estar coletivo e a busca do equilíbrio econômico, ambiental e social. Ressalta-se que as representações gráficas expressas nas embalagens podem contribuir para a compreensão dos significados que remetem à sustentabilidade. Para isso, realiza-se uma pesquisa com consumidores de produtos Natura Ekos, explorando as percepções sobre o consumo sustentável, a marca Natura e a embalagem do Frescor com óleo fixo de Buriti.

\section{Método de Pesquisa e Coleta de Dados}

Utilizando-se de pesquisa exploratória foram realizadas entrevistas em profundidade, semi estruturadas com 12 usuárias dos produtos Natura Ekos, considerando o critério de saturação. 0 perfil das entrevistadas consistia na faixa etária entre 22 e 50 anos, nível educacional de graduandas a mestrandas e acesso aos bens de uma classe média. A coleta dos dados considerou o processo de significação dos produtos Natura Ekos com o objetivo de identificar os significados simbólicos relacionados à sustentabilidade percebidos a partir da análise da embalagem Frescor com óleo fixo de Buriti.

\section{Análise e Discussão dos Dados}

Para fins de análise de conteúdo, as entrevistas foram transcritas e as manifestações 
verbais das usuárias foram organizadas por dimensões temáticas de acordo com as categorias de análise que consideram o processo de significação de Bourdieu (tabela 1). A análise realizada requereu interpretação subjetiva do pesquisador deste artigo, que observou as falas propriamente ditas, a entonação da voz das usuárias entrevistadas e as expressões demonstradas no momento da entrevista, utilizando como objeto de estudo a embalagem Frescor com óleo fixo de Buriti (figura 1).

Figura 1: Embalagem Frescor com óleo fixo de Buriti

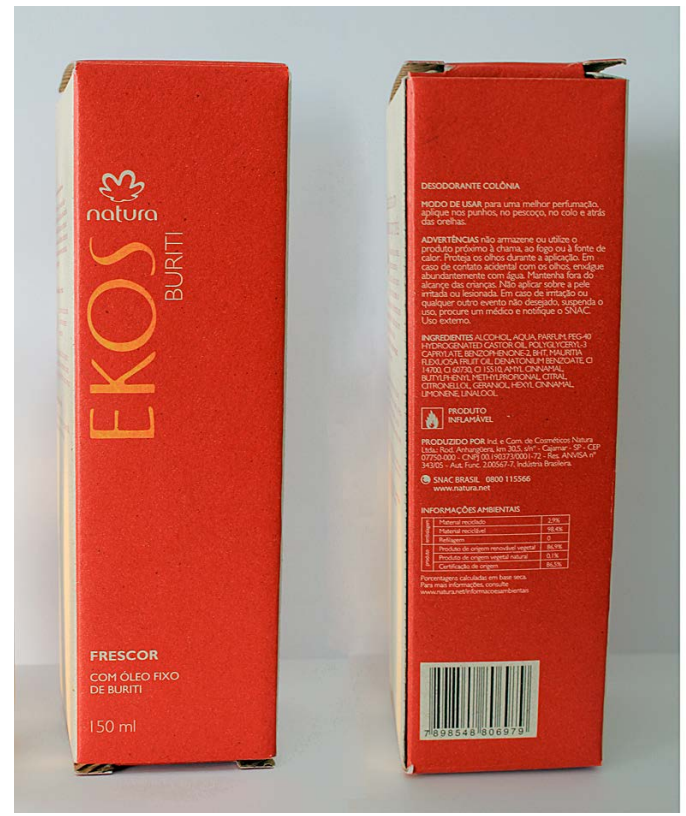

Fonte: a autora.

Tabela 1. Dimensões temáticas categorizadas com base nos Significados Simbólicos de Bourdieu.

\begin{tabular}{|c|c|c|c|c|}
\hline $\begin{array}{l}\text { Dimensões } \\
\text { Temáticas }\end{array}$ & $\begin{array}{l}\text { Percepções sobre } \\
\text { sustentabilidade }\end{array}$ & $\begin{array}{l}\text { Percepções sobre } \\
\text { o consumo de } \\
\text { cosméticos }\end{array}$ & Percepções sobre a Natura & $\begin{array}{l}\text { Percepções sobre a } \\
\text { embalagem }\end{array}$ \\
\hline $\begin{array}{l}\text { Categorias de } \\
\text { Análise dos } \\
\text { Significados } \\
\text { Simbólicos }\end{array}$ & \multicolumn{2}{|c|}{$\begin{array}{l}\text { campo (regras, condutas) + habitus (práticas } \\
\text { sociais) + capital cultural (gosto, movimento } \\
\text { ideológico de escolhas para o consumo. }\end{array}$} & $\begin{array}{l}\text { formas simbólicas, modo } \\
\text { de operação, consenso dos } \\
\text { sujeitos, contribuição do } \\
\text { poder simbólico daquele } \\
\text { que conhece o objeto }\end{array}$ & $\begin{array}{l}\text { objeto simbólico para } \\
\text { comunicar a } \\
\text { ideologia, (função, } \\
\text { sentido }\end{array}$ \\
\hline
\end{tabular}

Fonte: a autora.

\subsection{O campo da sustentabilidade}

Busca-se explorar nesta categoria de análise, os significados simbólicos que remetem ao campo da sustentabilidade que englobam o capital cultural e o habitus. Considera-se nesta 
abordagem, as percepções sobre o desenvolvimento sustentável e suas influências no processo de compra para o consumo de cosméticos, tais como regras, condutas, linguagens, crenças, práticas sociais e gostos (necessidades, preferências e desejo).

Verifica-se que, a partir das análises realizadas, que o campo da sustentabilidade é considerado um tema relevante pelas usuárias, como uma questão de educação, de conscientização, de integração das relações sociais e de incentivo para que cada um seja responsável por sua parte e contribua com atitudes de menor impacto ambiental e social. Destas considerações, destaca-se as seguintes falas: -"Que não é dificuldade, é educação eu vejo, falta de educação, de conscientização". Em contraponto, outra entrevistada afirma que: - "Eu acredito que é uma questão social...Mas acredito que essa consciência ela já faz parte das pessoas".

As entrevistadas também exprimem críticas e dúvidas, quanto a legitimação do campo da sustentabilidade, considerando que o uso do termo tem sido exagerado, confuso, saturado e que abala a credibilidade ao perceberem um discurso superficial, exemplificado pelas abordagens de marketing e influências da mídia. Apontam que este deve ser um princípio presente nas relações sociais e não ações isoladas que não fazem a diferença no ecossistema. Ressaltam que há muito a ser realizado e explicitado sobre a sustentabilidade. Destas considerações, destaca-se as seguintes afirmações: - "Uma palavra do momento!, Assim, tudo é para ser sustentável.., qualquer coisa é política de sustentabilidade, então acho tem uma grande confusão, no uso do termo ... dá para ver desde as propagandas, e da forma como as pessoas abordam. Não é uma meta empresarial, uma meta política, governamental, tem que ser um principio das pessoas em contribuírem $e$ colaborarem em todas as frentes e de todas as formas ... que isso esteja implícito e inserido no seu fazer no dia a dia". Outra entrevistada afirma que: -"É importante, mas acho que também tem muito de marketing ...em cima do conceito de sustentável, de sustentabilidade, ... claro se eu gostar, ... eu vou comprar...não ligo muito pra isso". Já outra reforça que: -"Ultimamente se fala muito nesta questão aí, do conceito estar batido, aí se está superado??? Eu acho que ainda não, nem vai tá, né? Visto que tem muita que a gente precisa fazer e melhorar na questão sustentável".

Deste modo, observa-se que o campo da sustentabilidade está em conflito, revelado por diferentes níveis de capitais culturais nas percepções das entrevistadas. Quanto mais elevado o capital cultural, mais consistente é a critica sobre esta temática, favorecendo ao surgimento de um desafio maior para atender as novas demanda de consumo nesta perspectiva. Em virtude de informações e posicionamentos inadequados no uso do conceito e na construção de discurso que apropriam-se do campo da sustentabilidade, revela-se que a credibilidade é fortemente abalada ao ser compreendida apenas como uma estratégia de marketing para estimular o consumo livre e, consequentemente, inibe a construção de novos hábitos neste viés.

Em relação ao processo de compra, as consumidoras buscam diversas características para adquirir um cosmético, tais como beleza, qualidade, confiança, baixo impacto ambiental, variedade de produtos, perceber resultados positivos pelo uso do produto, produtos naturais, antialérgico, inovação, selos ambientais, origem do produto e reaproveitamento de embalagens que são influenciadas por marcas conhecidas, por pesquisas anteriores, por orientações de vendedores e indicações médicas. Em virtude disso, destaca-se as seguintes práticas e gostos: "eu vou pelo que eu posso usar!!! E principalmente o que o dermatologista recomenda...uma coisa fisioterápica,... uma coisa mais natural". Outra entrevistada aponta que: -"se escuto as pessoas falarem, assim que o cosmético de tal marca é bom! aí eu me atiço!!! assim a minha curiosidade, 
aí vou na loja, converso com a vendedora, ela me explica tudo como é que é ...as novidades, aí eu compro, eu compro para testar, se for bom eu continuo comprando".

Quanto aos gostos e as práticas sociais identificadas nas entrevistadas ligadas ao consumo sustentável. Identificou-se nas entrevistadas a valorização de aspectos que remetem à sustentabilidade nos produtos para consumo, como mostra as seguintes falas: - "eu gosto de consumir produtos que eu sei que não agridem ao meio ambiente". Outra entrevistada afirma que: "Eu sempre olho qual o desenvolvimento do produto, se ele aquilo vai me beneficiar, ou não ... Eu identifico mais não só pelos selos que estão ali, mas pela origem do produto mesmo!". Já outra ressalta que: - Eu tento na minha vida, ser o mais sustentável possível. Mas é que não tem opções sabe?? Tem coisas que tu não tem opções...se eu consigo perceber e faço questão de consumir coisas com esse viés sustentável!".

Neste ponto, outra entrevistada valoriza estes aspectos, mas na prática afirma que: - "Eu, muito peco nesta parte porque eu não cuido. A sustentabilidade... eu percebo somente pelos produtos reciclados".

Quanto às preferências aos espaços físicos e virtuais para aquisição do produtos, diversificam-se entre sites, catálogos, lojas de departamentos, lojas no exterior, free shops, farmácias, supermercados, pontos de venda. Há usuárias que preferem apenas espaços físicos e destacam que não gostam de compras em espaços virtuais que pode ser visualizado na seguinte fala: - "Eu vou no ponto de venda, nunca compro pela internet por que não dá para ver o produto real, não dá para você tocar, abrir ou experimentar". Outra usuária afirma que prefere compras em espaços virtuais, como mostra a seguinte fala: - Geralmente faço uso da internet, até porque como passo muito tempo no trabalho, ... se eu preciso de um produto, olho na internet da farmácia e faço uma compra online que chega durante o dia".

Considerando o consumo sustentável, não ignora-se o gosto dos indivíduos porque entende-se que estes são intrínsecos à humanidade. Neste aspecto, observa-se o atendimento das necessidades, preferências e desejos interligada às interações ao meio ambiente. Já, que é lá que encontra-se disponíveis todas as riquezas necessárias para a sobrevivência. A diferença está na sua manutenção, com práticas que potencializem o equilíbrio econômico, ambiental e social. Estimulando a mesma atenção e cuidado com o corpo que evidencia-se nas entrevistas nas práticas de consumo. Para tanto, o mercado deve atender estas demandas, oferecendo soluções inovadoras ao resgatar os conflitos existentes no campo da sustentabilidade, transcendendo hábitos de uso de materiais e de processos com baixo impacto ambiental. Propõe-se a exploração de novas oportunidades de negócios, de produtos e serviços ressignificando-os no próprio habitat.

\subsection{As formas simbólicas para consumo de Natura Ekos}

Busca-se explorar nesta categoria de análise, os significados simbólicos ligados às formas simbólicas relacionadas à Natura Ekos. Para isso, considera-se nas percepções das entrevistadas, o modo de operação e o consenso para compreender o poder simbólico exercido nas interações com a marca. Há entrevistadas que percebem a Natura Ekos com produtos para consumo como algo mais natural, menos artificiais em relação aos concorrentes da marca, valorizando aspectos sobre a extração e o controle de matérias-primas de baixo impacto ambiental da biodiversidade brasileira, além de campanhas realizadas na mídia. 
Destacam ainda, a atuação diferenciada, a visão ampla sobre sustentabilidade que identifica oportunidades de negócio com a inserção de produtos ligados à natureza. Reconhecem a comercialização deste tipo de produto preocupado com o meio ambiente, pontuando historicamente a empresa como umas das pioneiras. Destas considerações destaca-se as seguintes falas: - "eu uso muitos produtos da Natura, mais do que das outras empresas ... eles me parecem mais naturais do que os outros, tipo parece que a gente está em contato direto com a essência do que ele é, parece menos artificial .... eu me identifico com a Natura em relação a isso porque eu vejo que eles tem este tipo de preocupação". Uma das entrevistadas sugere que: "Ela poderia falar um pouco mais, disseminar, a educação da sustentabilidade. Ah! podia fazer isso!"

Em contraponto, outras entrevistadas divergem desta perspectiva, afirmando que: - "A Natura tem produtos que são todos feitos através de elementos retirados do meio ambiente brasileiro, mas na verdade isso nada me assegura que o processo deles seja limpo ...Teria que pesquisar mais a fundo". Outra entrevistada acrescenta que: - "A Natura tem um marketing muito bom, eles vendem muita coisa boa, não sei se tudo é verdade ". Já outra, revela que: - "Eles trabalham com as comunidades locais, para poder levar esse conhecimento para eles, para que eles possam manter as florestas, seus locais de extração, que é ... uma forma manter o meio ambiente, porque antes eles tinham a extração usando muita mão de obra infantil".

Aponta-se que a Natura deve potencializar sua estratégia de negócio com a produção de cosméticos a partir de produtos naturais e com isso, promover novos aprendizados apropriandose dos novos hábitos de consumo para impulsionar a ressignificação das relações do homem com o meio ambiente. Para isso, deve aprofundar o seu discurso de sustentabilidade para não ser compreendido como uma mensagem superficial e intensificar as representações gráficas indicando os efeitos gerados pelos processos produtivos para assegurar a transparência das informações disponibilizadas, contribuindo ainda, para evitar associações com a mão de obra infantil. Sugere-se que retome-se informações geradas pelos inventários de análise de ciclo de vida do produto para validação dessas informações.

\subsection{A Embalagem como Objeto Simbólico}

Busca-se explorar nesta categoria de análise, os significados simbólicos ligados à embalagem Frescor com óleo fixo de Buriti, como um objeto simbólico. Para isso, considera-se as funções e os sentidos produzidos a partir da análise das representações gráficas presentes na embalagem e percebidas pelas entrevistadas.

Há entrevistadas que reconhecem a embalagem como um objeto simbólico que remete à sustentabilidade. Identificam representações gráficas que reforçam esta ideologia pela seleção de papel reciclado que pode ser reaproveitado novamente, pelo design da embalagem, pelas informações disponibilizadas sobre o modo de uso, advertências, o contexto histórico do Buriti, bem como, origem, modo de extração, localização geográfica e atividades realizadas em conjunto com as comunidades. Neste ponto, destaca-se as falas: -"É difícil ter as informações ambientais nas caixas dos produtos né? tu consegue identificar na marca dela o produto que tu está comprando e da onde que ele vem, e ele mostra que é comprado do cenário da Amazônia Brasileira, e uma coisa interessante também que os recursos da compra de insumos são destinados a projetos que visam o desenvolvimento local dessas comunidades". Outra entrevistada afirma que: -"Eu costumo olhar até os ingredientes, a fórmula, o modo de usar, né?". Quanto as 
advertências destaca-se: - "A parte gráfica ... uma simplicidade que remete à natureza. Mas isso não tá explícito!!!"

Em contraponto, há entrevistadas que exprimem dúvidas em relação ao que é o produto, como funciona o processo de produção, se o processamento das matérias tem baixo impacto ambiental, como evidencia-se nas falas: - "na própria extração o Buriti, então será que eles tem plantio para extrativista, será que eles fazem esta lógica de plantar o Buriti??? Ou vão usar aquele que está disponivel, aquela comunidade local que usa também para fins de artesanato, então eu não sei a embalagem em si, como uma proposta que remeta uma ideia de sustentável". Outra entrevistada complementa que: - "Eu sei que para retirar, extrair os óleos fixos do buriti, aqui no caso, tem que fazer um processo de destilação". Quanto a matéria-prima da embalagem outra entrevistada afirma que: - "eu não sei se eu acredito tanto nessa questão do produto ser sustentável, só pelo papel reciclado! Hoje em dia, às vezes, tu pode fazer um produto com alguma outra matéria realmente reaproveitável".

Uma das entrevistadas diverge desta perspectiva sobre a compreensão do que é o produto pela embalagem, afirmando que: - "eles não falam o que é o produto na verdade, isso dá uma dúvida assim na hora da compra". E sugere: - "seria mais relevante mesmo a imagem da frutinha, alguma outra coisa que me chamasse a atenção". Outra entrevistada apresenta dúvidas na compreensão das informações expressas, como destaca-se na fala: - "Produto de origem renovável, mas ele não diz qual né? Ai pode dizer qualquer coisa!!! Quem garante?".

Os hábitos de leitura da embalagem divergem-se entre as entrevistadas, como destaca-se as falas: - "Eu leio embalagens!! Eu olho pra tudo!". Outra, diverge afirmando que: -"Estas informações ambientais que eles colocam, que na verdade eu nunca tinha visto, nunca tinha parado para analisar".

Portanto, aponta-se que a Natura pode potencializar os sentidos gerados pela embalagem como um objeto simbólico inserido na cultura para o consumo sustentável. Para tanto, deve enfatizar a sua função apresentando uma comunicação transparente nas representações gráficas aplicadas na embalagem, a fim de solucionar dúvidas e confusões geradas pela interpretações inadequadas sobre o produto que podem comprometer o seu consumo. Pontua-se uma linguagem simples e clara com uma mensagem profunda para não ser confundida com um discurso superficial, considerando aspectos sobre a matéria-prima, o processo produtivo e de descarte, além de evidenciar transparência e ética nas relações que envolvem a produção de seus cosméticos. Deste modo, intervenções de design podem contribuir para atrair a atenção de usuárias que consideram ou não relevantes as representações gráficas expressas nas embalagens.

\section{Considerações Finais}

Este artigo apresentou a análise e discussão sobre os resultados da pesquisa exploratória realizada a partir de entrevistas em profundidade com 12 consumidoras de produtos Natura Ekos. Para isso, foi realizada a pesquisa com base nos processos de significação de Bourdieu, optando-se pela identificação dos significados simbólicos para embasamento da construção, aplicação, análise e discussão das percepções das usuárias.

Deste modo, foram identificados na análise do conteúdo das entrevistas, significados simbólicos que podem potencializar a comunicação de sustentabilidade nas embalagens por meio 
de intervenções de design.

Com a análise e a discussão dos resultados apontou-se diretrizes projetuais para que designers possam explorar a pesquisa para a proposição de soluções mais complexas e inovações que aprofundem os significados simbólicos na construção dos discursos representados nas embalagens que remetem à sustentabilidade de modo intrínseco ao projeto.

Destaca-se ainda, que a embalagem é um objeto simbólico que favorece a aprendizagem social, tendo em vista uma cultura mais sustentável para o bem-estar coletivo com equilíbrio econômico, ambiental e social. Compreendeu-se que em futuras pesquisas pode-se explorar as práticas de leitura das usuárias para obter novos insumos para projetos de design de embalagens considerando a construção de significado simbólicos mais profundos para o campo da sustentabilidade.

\section{Referências}

BAUDRILLARD, Jean. A sociedade de consumo. Lisboa: Edições 70, 2007.

BOURDIEU, Pierre. A Distinção: crítica social do julgamento. Porto Alegre, Editora Zouk, 2007.

BOURDIEU, Pierre. O Poder Simbólico. Rio de Janeiro, Bertrand Brasil, 1989.

CAMPBELL, Colin. Consumo logo sei que existo: as bases metafísicas do consumo moderno. in BARBOSA, LÍVIA \& CAMPBELL, Colin (Org.). Cultura, consumo e identidade. Rio de Janeiro: FGV, p. 47-64, 2006.

DOUGLAS, MARY \& ISHERWOOD, Baron. O mundo dos bens. Rio de Janeiro: UFRJ, 2006.

HOLT. Douglas. Does cultural capital structure American consumption? Journal of Consumer Research, 25, p.1-25, 1998.

LIPOVETSKY, Gilles. Os tempos hipermodernos. São Paulo: Editora Barcarolla, 2004.

MCCRACKEN, Grant. Cultura e consumo. Rio de Janeiro: Mauad, 2003.

MILLER, Daniel. Consumo como cultura material. Horizontes Antropológicos, vol. 13, n. 28, Porto Alegre, July/Dec. 2007.

MORIN, Edgar. Os sete saberes necessários à educação do futuro. Brasília, DF: UNESCO, 2000, p. 70-82.

ONU - Organização das Nações Unidas. (Acesso em: 02 nov. 2013). Disponível em: <http://www.onu.org.br/a-onu-em-acao/a-onu-e-o-meio-ambiente/>.

Natura. (Acesso em: 02 nov. 2013). Disponível em: <http://www.natura.com.br/institucional>.

Natura Ekos. (Acesso em: 02 nov. 2013). Disponível em: <http://www.naturaekos.com.br/?gclid=CJOVhY-q2LMCFQ4EnQodSSEAVA>.

Relatório Natura 2012. (Acesso em: 02 nov. 2013). Disponível em: <http://natura.infoinvest.com.br/ptb/4264/RelatrioAnual_2012_CompletoGRI_Port.pdf>. 